\title{
Analisis Faktor-Faktor yang Mempengaruhi Tingkat Kelelahan pada Pekerjaan Berulang di Industri Manufaktur
}

\author{
Renny Septiari ${ }^{1}$ \\ ${ }^{1}$ Institut Teknologi Nasional (ITN) Malang \\ e-mail address : rennyseptiari@lecturer.itn.ac.id
}

\section{Keywords:}

tingkat kelelahan, shift kerja, beban kerja, lingkungan kerja fisik, smartPLS

\section{PENDAHULUAN}

Duduk berkepanjangan dalam bekerja banyak dilakukan oleh para pekerja sehingga menyebabkan masalah pada lutut dan kaki terkait pekerjaan yang menetap. Duduk berkepanjangan juga sangat merugikan untuk beberapa kondisi kesehatan [1,2,3,4]. Posisi duduk dalam bekerja, dapat membuat tubuh terasa nyaman selama melaksanakan pekerjaan karena dengan duduk sambil bekerja dapat dengan baik melakukan pekerjaan dan hasilnya cukup memuaskan. Tetapi terlalu lama duduk dalam bekerja dapat menimbulkan gangguan dalam tubuh. Seperti otot kaku, gangguan keseimbangan, dan gangguan monotoris tubuh. Duduk berkepanjangan dapat menyebabkan gangguan kesehatan seperti obesitas, hipertensi, diabetes type 2 , penyakit kardiovaskular dan peningkatan mortalitas sebab perilaku ini dilakukan secara menetap karena pekerjaan yang harus dilakukan [3,5,6]. Hal ini dikarenakan tubuh akan beradaptasi dengan setiap kegiatan yang biasa dilakukan. Dengan duduk seharian, tubuh akan beradaptasi dengan kebiasaan tersebut daripada aktivitas lain yang membutuhkan lebih banyak gerakan. Efeknya, tubuh bisa kehilangan keseimbangan, kekuatan dan bahkan mempunyai cara berjalan yang buruk. Adapun resiko yang biasa terjadi apabila bekerja dengan duduk selama 8 sampai 10 jam dapat menimbulkan nyeri di leher dan tengkuk, wasir/ambeien serta sakit punggung, hal ini dikarenakan otot yang menjadi kaku akibat duduk terlalu lama.

Untuk kebanyakan orang dengan umur antara 18 - 65 tahun, sebagian besar mereka lebih banyak menghabiskan waktu di tempat kerja dalam keadaan duduk menetap untuk beberapa pekerjaan. Duduk menetap pada waktu lama pada saat kerja atau santai berdampak buruk pada kesehatan [7]. Duduk berkepanjangan sepanjang waktu menunjukkan hasil yang merugikan terutama pada bagian tulang belakang [8]. Pada posisi duduk apabila dilakukan secara terus-menerus akan mengakibatkan meningkatnya tekanan pada tulang belakang jika posisi duduk dilakukan dengan tidak benar. Hal ini dikarenakan tekanan pada bagian tulang belakang meningkat pada saat duduk, dibandingkan dengan saat berdiri ataupun berbaring. Akibat dari perilaku menetap sepanjang waktu memberikan dampak yang

https://doi.org/10.20961/mekanika.v19i1.39924 
merugikan pada hasil kesehatan fisiologis dan terbukti merusak kesehatan $[9,10]$.

Pekerjaan pengepakan minuman merupakan salah satu pekerjaan yang tergolong dalam repetitive (pengulangan) dan monoton, karena aktivitas yang sama dilakukan lebih dari satu kali dalam proses penyelesaian suatu produk [11]. Walaupun tenaga yang dikeluarkan tidak terlalu banyak dalam melakukan pekerjaan ini tetapi beban kerja yang dirasakan pekerja terasa lebih besar karena rutinitas yang dilakukan setiap harinya dan tidak ada variasi dalam bekerja. Sikap kerja yang statis dalam jangka waktu yang lama lebih cepat menimbulkan keluhan pada sistem muskuloskeletal. Pekerjaan statis dan berulang-ulang dapat menyebabkan kelelahan dan kebosanan [12,13].

Penelitian tentang analisa faktor yang berhubungan dengan kelelahan telah dilakukan oleh $[18,19,20]$ dengan variabel usia, status gizi, masa kerja, sikap kerja, beban kerja sebagai variabel/faktor yang di analisa. Sedangkan pada penelitian ini akan menganalisis tingkat kelelahan dengan mengkombinasikan faktor kecepatan kerja, denyut jantung dan lingkungan kerja yang diwakili oleh pencahayaan. Hasil dari penelitian sebelumnya menunjukkan bahwa masing-masing variabel berpengaruh positif dan signifikan terhadap tingkat kelelahan yang terjadi terhadap karyawan.

Dari kombinasi variabel/faktor yang akan digunakan, pada penelitian ini akan ditentukan variabel/faktor yang mempengaruhi tingkat kelelahan pada pekerjaan berulang yang dilakukan dengan duduk. Diharapkan dengan diketahuinya variabel/faktor yang berpengaruh dapat dilakukan pengurangan atau dieliminir sehingga kelelahan tidak cepat timbul dan pada akhirnya kinerja operator dapat lebih meningkat.

\section{LANDASAN TEORI}

Telah dijelaskan sebelumnya bahwa penelitian ini akan membahas pengaruh shift kerja, beban kerja dan lingkungan kerja fisik yang menjadi variabel/faktor yang mempengaruhi tingkat kelelahan serta analisa menggunakan SmartPLS. Adapun penjelasan mengenai variabel/faktor tersebut adalah:

$>$ Kelelahan Kerja

Kelelahan merupakan suatu bagian dari mekanisme tubuh untuk melakukan perlindungan agar tubuh terhindar dari kerusakan yang lebih parah, dan akan kembali pulih apabila melakukan istirahat [14].

$>$ Shift kerja

[15] mendefinisikan shiftkerja sebagai waktu kerja organisasi dengan tim yang berbeda secara berurutan mencakup lebih dari 8 jam kerja perhari biasa, menjadi 24 jam. Beberapa orang bekerja shiftdengan rotasi sementara, sementara yang lain dijadwalkan secara teratur yaitu shiftpagi, sore dan malam.

$>$ Beban kerja

Menurut [16] beban kerja adalah suatu kondisi dari pekerjaan dengan uraian tugasnya yang harus diselesaikan pada batas waktu tertentu. Sedangkan menurut Hart dan Staveland, dalam [14] menyatakan bahwa beban kerja merupakan suatu yang muncul dari interaksi antara tuntutan tugas-tugas lingkungan kerja dimana digunakan sebagai tempat kerja. Beban kerja kadang-kadang di definisikan secara operasional pada faktorfaktor seperti tuntutan tugas dan upaya-upaya yang dilakukan untuk melakukan pekerjaan.

Lingkungan kerja fisik

adalah suatu tempat yang terdapat sejumlah kelompok dimana di dalamnya terdapat beberapa fasilitas pendukung untuk mencapai tujuan perusahaan sesuai dengan visi dan misi perusahaan [17].

Paparan Lingkungan fisik adalah salah satu aspek yang dapat menimbulkan gangguan terhadap suasana kerja dan dapat berpengaruh terhadap kondisi dari masingmasing operator. Dengan lingkungan kerja yang nyaman diharapkan dapat meningkatkan kinerja karyawan secara optimal dan produktif tanpa ada gangguan dan rasa cemas saat melaksanakan aktivitas kegiatan pengepakan.

Smart PLS 
Partial Least Square (PLS) adalah suatu metode yang berbasis keluarga regresi yang dikenalkan oleh Herman O.A Wold untuk penciptaan dan pembangunan model dan metode untuk ilmu-ilmu sosial dengan pendekatan yang berorientasi pada prediksi. PLS memiliki asumsi data data penelitian bebas berdistribusi (Distribution Free), artinya data penelitian tidak mengacuh pada salah satu distribusi tertentu (misalnya distribusi normal). PLS merupakan metode alternatif dari Structural Equation Modelling (SEM) yang dapat digunakan untuk mengatasi permasalahan hubungan diantara variabel yang kompleks namun ukuran sampel datanya kecil (30 sampai 100), mengingat SEM memiliki ukuran sampel data minimal 100.

\section{METODOLOGI PENELITIAN}

\section{Identifikasi variabel}

Adapun variabel yang mempengaruhi kombinasi perubahan posisi kerja dapat dilihat pada tabel 1 .

Tabel1. Identifikasi Variabel

\begin{tabular}{|c|c|}
\hline Variabel & Definisi \\
\hline \multirow{18}{*}{$\begin{array}{l}\text { Kelelahan } \\
\text { kerja }\end{array}$} & Untuk pengukuran tingkat \\
\hline & kelelahan menggunakan \\
\hline & Kuesioner Alat Ukur \\
\hline & Perasaan Kelelahan Kerja \\
\hline & (KAUPK2) yang akan \\
\hline & $\begin{array}{ll}\text { diberikan kepada } & \text { masing- } \\
\text { masing } & \text { operator }\end{array}$ \\
\hline & pengepakan. Penilaian \\
\hline & tingkat kelelahan memakai \\
\hline & $\begin{array}{l}\text { skala likert dengan asumsi } \\
\text { sebagai berikut : } 1=\text { Tidak }\end{array}$ \\
\hline & $2=$ Kadang-kadang ; $3=$ \\
\hline & Sering $; 4=$ selalu \\
\hline & $\begin{array}{lr}\text { Adapun } & \text { hasil tingkat } \\
\text { kelelahan } & \text { merupakan }\end{array}$ \\
\hline & jawaban pilihan dari \\
\hline & masing-masing operator \\
\hline & yang paling banyak dipilih \\
\hline & dari 17 pertanyaan yang \\
\hline & diajukan yang terbagi dalam \\
\hline & 4 kelompok yaitu \\
\hline
\end{tabular}

\begin{tabular}{|c|c|}
\hline & $\begin{array}{l}\text { konsentrasi (A), lelah fisik } \\
\text { (B), kecemasan (C), dan } \\
\text { motivasi kerja (D). }\end{array}$ \\
\hline Shift kerja & $\begin{array}{l}\text { Shift kerja yang digunakan } \\
\text { pada penelitian ini adalah } \\
\text { shift kerja pagi dan siang } \\
\text { dilihat dari waktu kecepatan } \\
\text { pengepakan yang terpakai. } \\
\text { Hal ini digunakan untuk } \\
\text { melihat perbedaan yang } \\
\text { terjadi antara aktivitas } \\
\text { pengepakan yang dilakukan } \\
\text { pada pagi dan sore hari. }\end{array}$ \\
\hline Beban kerja & $\begin{array}{l}\text { Beban kerja diukur dari } \\
\text { tingkat rata-rata denyut } \\
\text { jantung yang terjadi saat } \\
\text { melakukan } \\
\text { pengepakan dan rata-rata } \\
\text { konsumsi oksigen yang } \\
\text { terpakai. }\end{array}$ \\
\hline $\begin{array}{l}\text { Lingkungan } \\
\text { kerja fisik }\end{array}$ & $\begin{array}{l}\text { Pengukuran lingkungan } \\
\text { kerja fisik menggunakan } \\
\text { kuesioner yang terdiri dari } \\
11 \text { pertanyaan yang terbagi } \\
\text { menjadi } 5 \text { kelompok yaitu } \\
\text { Keadaan Udara (X), } \\
\text { Kebisingan (Y), Getaran } \\
\text { (Z), Pencahayaan (V), dan } \\
\text { Penataan Ruang (W). } \\
\text { Penilaian lingkungan fisik } \\
\text { menggunakan skala likert } \\
\text { dengan asumsi : } 1=\text { sangat } \\
\text { tidak setuju, } 2=\text { tidak } \\
\text { setuju, } 3=\text { setuju, } 4=\text { setuju } \\
\text { sekali. }\end{array}$ \\
\hline
\end{tabular}

Dari variabel yang digunakan pada tabel 1., dapat dirumuskan hipotesis sebagai berikut :

H1 : Shift kerja berpengaruh terhadap posisi kerja

H2 : Beban kerja berpengaruh terhadap posisi kerja

H3 : Lingkungan fisik berpengaruh terhadap posisi kerja 
H4 : Posisi kerja berpengaruh terhadap tingkat kelelahan

\section{Penentuan Indikator}

Berdasarkan identifikasi variabel dari tabel 1. Maka dapat ditentukan indikator pengukurnya seperti pada tabel 2.

Tabel 2. Variabel Independen dan Variabel Dependen

\begin{tabular}{|c|c|c|}
\hline $\begin{array}{c}\text { Variabel } \\
\text { Independen }\end{array}$ & & Indikator \\
\hline \multirow[t]{2}{*}{ Shift kerja } & $\mathrm{X} 11$ & $\begin{array}{l}\text { Waktu kecepatan } \\
\text { pengepakan shift } \\
\text { pagi }\end{array}$ \\
\hline & $\mathrm{X} 12$ & $\begin{array}{l}\text { Waktu kecepatan } \\
\text { pengepakan shift } \\
\text { siang }\end{array}$ \\
\hline \multirow[t]{2}{*}{ Beban kerja } & $\mathrm{X} 21$ & $\begin{array}{l}\text { Rata-rata denyut } \\
\text { jantung }\end{array}$ \\
\hline & $\mathrm{X} 22$ & $\begin{array}{l}\text { Rata-rata } \\
\text { konsumsi oksigen }\end{array}$ \\
\hline \multirow{5}{*}{$\begin{array}{l}\text { Lingkungan } \\
\text { kerja fisik }\end{array}$} & $\mathrm{X} 31$ & Keadaan udara \\
\hline & $\mathrm{X} 32$ & Kebisingan \\
\hline & X33 & Getaran \\
\hline & X34 & Pencahayaan \\
\hline & X35 & Penataan ruang \\
\hline $\begin{array}{l}\text { Variabel } \\
\text { Dependen }\end{array}$ & & Indikator \\
\hline \multirow[t]{3}{*}{ Posisi kerja } & Y11 & Posisi duduk saja \\
\hline & Y12 & Posisi berdiri saja \\
\hline & Y13 & $\begin{array}{l}\text { Posisi duduk dan } \\
\text { berdiri bergantian }\end{array}$ \\
\hline \multirow{4}{*}{$\begin{array}{l}\text { Tingkat } \\
\text { kelelahan }\end{array}$} & Y21 & Konsentrasi \\
\hline & Y22 & Lelah fisik \\
\hline & Y23 & Kecemasan \\
\hline & Y24 & Motivasi kerja \\
\hline
\end{tabular}

\section{HASIL DAN PEMBAHASAN}

Dari penelitian yang dilakukan $[18,19,20]$ dengan bantuan SPSS metode analisis Chi-square disebutkan bahwa umur dan sikap kerja, beban kerja dan shift kerja berpengaruh positif dan signifikan terhadap kelelahan.
Pada penelitian ini, metode yang digunakan adalah Smart PLS. Tujuannya selain mencari hubungan antar variabel independen dan dependen juga untuk menentukan faktor yang paling berpengaruh terhadap tingkat kelelahan dari beberapa variabel independen yang telah ditentukan.

Dari beberapa faktor yang mempengaruhi tingkat kelelahan yang ditentukan oleh posisi kerja yang dipengaruhi oleh shift kerja, beban kerja, dan lingkungan kerja fisik akan dianalisa faktor apakah yang paling berpengaruh terhadap pekerjaan pengepakan yang hanya dilakukan dengan duduk saja sepanjang waktu.

Tabel 3. Outer Loading Variabel

\begin{tabular}{|c|l|c|}
\hline \multicolumn{2}{|c|}{ Indikator } & $\begin{array}{c}\text { Outer } \\
\text { Loading }\end{array}$ \\
\hline X11 & $\begin{array}{l}\text { Waktu kecepatan } \\
\text { pengepakan shift } \\
\text { pagi }\end{array}$ & 0,892 \\
\hline X12 & $\begin{array}{l}\text { Waktu kecepatan } \\
\text { pengepakan shift } \\
\text { sore }\end{array}$ & 0,927 \\
\hline X21 & $\begin{array}{l}\text { Rata-rata denyut } \\
\text { jantung }\end{array}$ & 0,980 \\
\hline X22 & $\begin{array}{l}\text { Rata-rata konsumsi } \\
\text { oksigen }\end{array}$ & 0,797 \\
\hline X31 & Keadaan udara & 0,887 \\
\hline X32 & Kebisingan & 0,925 \\
\hline X33 & Getaran & 0,888 \\
\hline X34 & Pencahayaan & 0,932 \\
\hline X35 & Penataan ruang & 0,865 \\
\hline
\end{tabular}

Dari tabel 3. dapat dijelaskan bahwa indikator yang paling dominan sebagai refleksi dari variabel shift kerja adalah indikator waktu kecepatan pengepakan shift pagi dengan nilai outer loading 0,918 yang berarti sumbangan indikator terhadap nilai laten variabelnya sebesar 91,8\%. Untuk variabel beban kerja indikator yang paling dominan adalah denyut jantung dengan nilai 0,959 dan lingkungan kerja fisik faktor yang paling dominan adalah keadaan udara dengan nilai 0,935 . 
Tabel 4. Outer Weight

\begin{tabular}{|c|c|c|}
\hline \multicolumn{2}{|r|}{ Indikator } & Outer Weight \\
\hline Y11 & $\begin{array}{l}\text { Posisi } \quad \text { duduk } \\
\text { saja }\end{array}$ & 0,378 \\
\hline Y12 & $\begin{array}{l}\text { Posisi berdiri } \\
\text { saja }\end{array}$ & 0,382 \\
\hline Y13 & $\begin{array}{lr}\text { Posisi } & \text { duduk } \\
\text { dan } & \text { berdiri } \\
\text { bergantian } & \end{array}$ & 0,318 \\
\hline Y21 & Konsentrasi & 0,236 \\
\hline Y22 & Lelah fisik & 0,227 \\
\hline Y23 & Kecemasan & 0,311 \\
\hline $\mathrm{Y} 24$ & Motivasi kerja & 0,295 \\
\hline
\end{tabular}

Dari tabel 4. Dapat dijelaskan bahwa data pada tabel menunjukkan bahwa nilai outer weight semua indikator mempunyai nilai positif yang mengindikasikan kontribusi positif indikator pada pengukuran variabel posisi kerja. Sedangkan pada variabel tingkat kelelahan data menunjukkan bahwa nilai outer weight semua indikator mempunyai nilai positif yang mengindikasikan kontribusi positif indikator pada pengukuran variabel tingkat kelelahan, kecuali untuk motivasi kerja yang mengindikasikan kontribusi negatif terhadap tingkat kelelahan yang berarti motivasi kerja tidak memberikan pengaruh pada variabel tingkat kelelahan.

Tabel 5.Nilai AVE Posisi Duduk

\begin{tabular}{|l|r|}
\hline Shift kerja & 0.717 \\
\hline Beban kerja & 0.911 \\
\hline Lingkungan fisik & 0.936 \\
\hline Posisi kerja & 0.74 \\
\hline Tingkat kelelahan & 0.914 \\
\hline
\end{tabular}

Nilai average variance extracted (AVE) digunakan untuk mengukur banyaknya varians yang dapat ditangkap oleh konstruknya dibandingkan dengan variansi yang ditimbulkan oleh kesalahan pengukuran. Nilai AVE digunakan untuk menguji akar kuadrat dari setiap variabel, apakah korelasi lebih besar dari setiap konstruk laten (Grefen dan Straub, 2005: 94). Selain itu, nilai AVE digunakan sebagai syarat validitas diskriminan tercapai (Wijayanto,
2008: 66). Nilai AVE minimum untuk menyatakan bahwa keandalan telah tercapai adalah sebesar 0,50 (Wijayanto, 2008: 66). Nilai AVE dibawah 0,50 menunjukkan bahwa indikator memiliki rata-rata tingkat error yang lebih tinggi.

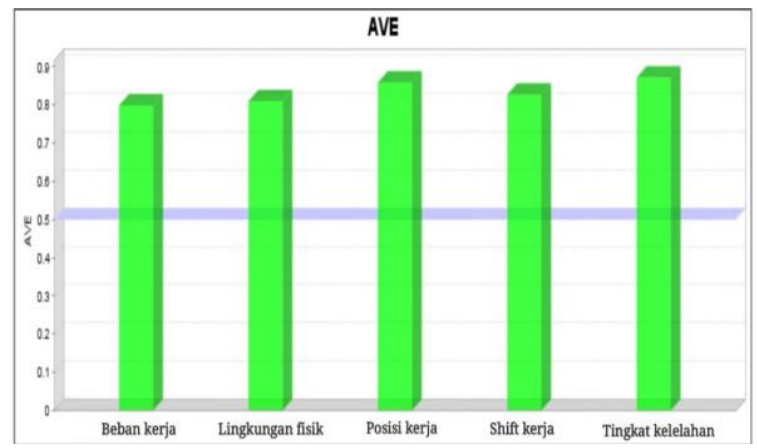

Gambar 1. Grafik AVE Posisi Duduk

Dari tabel 5 dan gambar 1 terlihat bahwa nilai AVE untuk semua variabel $\geq 0,50$. Hal ini menunjukkan bahwa semua variabel yang digunakan pada model memenuhi syarat validitas (valid).

Tabel 6. Nilai Composite Reliability Posisi Duduk

\begin{tabular}{|l|l|}
\hline Shift kerja & 0,905 \\
\hline Beban kerja & 0,887 \\
\hline Lingkungan fisik & 0,955 \\
\hline Posisi kerja & 0,948 \\
\hline Tingkat kelelahan & 0,964 \\
\hline
\end{tabular}

Suatu konstruk atau variabel dikatakan memenuhi composite reliability jika memiliki nilai composite reliability $\geq 0,70$. 


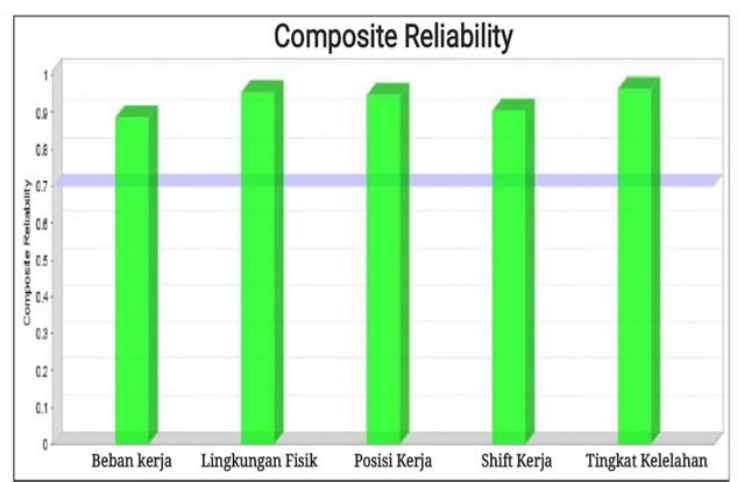

Gambar 2. Grafik Composite Reliability Posisi Duduk

Dari tabel 6. dan gambar 2 terlihat bahwa nilai composite reliability untuk semua variabel $\geq$ 0,70 . Hal ini menunjukkan bahwa semua variabel yang digunakan pada model memenuhi syarat reliabilitas (reliabel).

Tabel 7. Hasil Hipotesis Pengujian Pengaruh Langsung Posisi Duduk

\begin{tabular}{|l|l|l|l|}
\hline & $\begin{array}{l}\text { Path } \\
\text { Coeffi } \\
\text { cient }\end{array}$ & $\begin{array}{l}\text { P } \\
\text { Valu }\end{array}$ & $\begin{array}{l}\text { Keteran } \\
\text { gan }\end{array}$ \\
\hline $\begin{array}{l}\text { Shift kerja } \rightarrow \\
\text { Posisi kerja } \\
\text { (Y1) }\end{array}$ & 2,080 & $\begin{array}{l}0,03 \\
8\end{array}$ & $\begin{array}{l}\text { Signifik } \\
\text { an }\end{array}$ \\
\hline $\begin{array}{l}\text { Beban kerja } \rightarrow \\
\text { Posisi kerja } \\
\text { (Y1) }\end{array}$ & 0,549 & 0,58 & $\begin{array}{l}\text { Tidak } \\
\text { Signifik } \\
\text { an }\end{array}$ \\
\hline $\begin{array}{l}\text { Lingkungan } \\
\text { fisik } \rightarrow \text { Posisi } \\
\text { kerja (Y1) }\end{array}$ & 1,267 & 0,20 & $\begin{array}{l}\text { Tidak } \\
\text { Signifik } \\
\text { an }\end{array}$ \\
\hline $\begin{array}{l}\text { Posisi kerja } \rightarrow \\
\text { Tingkat } \\
\text { kelelahan (Y2) }\end{array}$ & 1,878 & 0,06 & $\begin{array}{l}\text { Signifik } \\
\text { an }\end{array}$ \\
\hline
\end{tabular}

Pengaruh langsung shift kerja terhadap posisi kerja adalah positif dan signifikan dengan besaran koefisien jalur adalah 2,080 dan $p$ value kurang dari 0,1. Pengaruh langsung beban kerja terhadap posisi kerja adalah positif dan tidak signifikan dengan besaran koefisien jalur adalah 0,549 dan $p$ value lebih dari 0,1. Pengaruh langsung lingkungan fisik adalah positif dan tidak signifikan dengan besaran koefisien jalur adalah 1,267 dan $p$ value lebih dari 0,1. Pengaruh langsung posisi kerja terhadap tingkat kelelahan adalah positif dan signifikan dengan besaran koefisien jalur adalah 1,878 dan $p$ value kurang dari 0,1 . Seperti tampak pada gambar 3 .

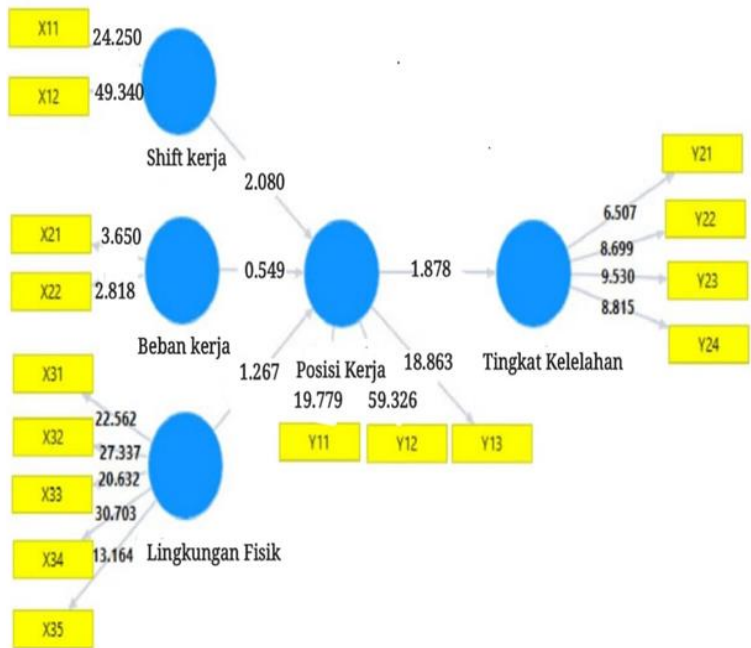

Gambar 3. Diagram Jalur Hasil Pengujian Hipotesis Posisi Duduk

Dengan berpengaruhnya shift kerja terhadap tingkat kelelahan secara positif dan signifikan dengan besaran koefisien jalur adalah 2,080 diharapkan operator pengepakan dapat lebih menjaga diri agar kondisi tubuh dapat tetap terjaga dan fit saat bekerja baik saat shift pagi maupun sore. Demikian pula untuk perusahaan agar dapat lebih memperhatikan kondisi karyawan saat bekerja di shift sore, dengan memberikan fasilitas tambahan agar kondisi karyawan yang bekerja saat itu dapat tetap fit sampai pekerjaan selesai dilakukan.

\section{Kesimpulan}

Faktor yang mempengaruhi tingkat kelelahan yang terjadi saat proses pengepakan yang dilakukan dengan posisi duduk adalah shift kerja yang berpengaruh positif dan signifikan. Hal ini mencerminkan bahwa performa yang dihasilkan saat bekerja berbeda antara shift pagi dan sore. Perbedaan tersebut dapat dilihat dari tingkat kecepatan pengepakan yang dihasilkan masingmasing operator saat bekerja di waktu pagi atau sore hari. Tingkat kelelahan akan cepat timbul seiring dengan melemahnya tenaga seseorang dan biasanya berbeda antara shift pagi dan sore. 
Dimana saat pagi tenaga masih segar-segarnya dibandingkan bekerja di shift sore disaat tenaga sedang berjalan menurun sehingga performa kerja juga turun akibat tingkat kelelahan yang dialami.

\section{Daftar Pustaka}

[1] M.S. Tremblay, R.C. Colley, T.J. Saunders, et al., "Physiological, and health implications of a sedentary lifestyle", Applied Physiologi, Nutrition, and Metabolism, vol. 35, no. 6, pp. 725-40, 2010.

[2] G.N. Healy, C.E. Matthews, D.W. Dunstan, et al., "Sedentary time and cardio-metabolic biomarkers in US adults: NHANES 2003-06", European Heart Journal, vol. 32, no. 5, pp. 5907, 2011.

[3] A.R. Homer, N. Owen, D.W. Dunstan, "Too much sitting and dysglycemia: Mechanistic links and implications for obesity", Current Opinion in Endocrine and Metabolic Research, vol. 4, pp. 42-49, 2019.

[4] C. Bontrup, et al. "Low back pain and its relationship with sitting behaviour among sedentary office workers", Applied Ergonomics, vol. 81, 2019.

[5] P.C. Dempsey, et al., "Prolonged uninterrupted sitting increases fatigue in type 2 diabetes", Diabetes Research and Clinical Practice, vol. 135, pp. 128-133, 2018.

[6] I.K. Thorsen, et al. "The effect of frequency of activity interruptions in prolonged sitting on postprandial glucose metabolism: A randomized crossover trial", Metabolism, vol. 96, pp. 1-7, 2019.

[7] D.W. Dunstan, et al., "Too much sitting - A health hazard", Diabetes Research and Clinical Practice, vol. 97, pp. 368-376, 2012.

[8] B.C. Nairn, N.R. Azar, J.D.M. Drake, "Transient pain developers show increased abdominal muscle activity during prolonged sitting", Journal of Electromyography and Kinesiology, vol. 23, no. 6, pp. 1421-1427, 2013.

[9] V. Baruch, et al., "Sedentary behavior and physiological health determinants in male and female college students", Physiology \& Behavior, vol. 204, pp.277-282, 2019.

[10] Y. Wang, et al., "Persuasive technology in reducing prolonged sedentary behavior at work: A systematic review", Smart Health, vol. 7-8, pp.19-30, 2018.

[11] R. Septiari, Pratikto, P.B. Santoso, I.P. Tama, "The influence of combining sitting and standing position in plastic glass packaging", Journal of Engineering Science and Technology, vol.13, no.2, pp.373-380, 2018.
[12] B.D. Farahmand, A.M. Boroujerdian, "Effect of road geometry on driver fatigue in monotonous environments: A simulator study", Transportation Research Part F: Traffic Psychology and Behaviour, vol 58, pp. 640-651, 2018.

[13] J. Santos, et al., "The influence of task design on upper limb muscles fatigue during low-load repetitive work: A systematic review", International Journal of Industrial Ergonomics, vol. 52, pp.78-91, 2016.

[14] Tarwaka, "Keselamatan dan Kesehatan Kerja:Manajemen dan Implementasi K3 di Tempat Kerja", Surakarta : Harapan Press, 2014.

[15] R.G. Stevens, et al.," Considerations of circadian impact for defining 'shift work' in cancer studies: IARC Working Group Report", Occup Envion Med,vol. 68, pp.154-162, 2011.

[16] Munandar, "Psikologi Kepribadian.", Jakarta: PT. Raja Grafindo Persada, 2014.

[17] Sedarmayanti, " Manajemen Sumber Daya Manusia”. Bandung: Refika Aditama, 2013.

[18] Januar, dkk., "Faktor-Faktor Yang Berhubungan Dengan Kelelahan Kerja Pada Pekerja Konveksi Bagian Penjahitan Di Cv.Aneka Garment Gunungpati Semarang", Jurnal Kesehatan Masyarakat (E-Journal), vol. 2, no. 2, 2014. online Di http://EjournalS1.Undip.Ac.Id/Index.Php/Jkm.

[19] M. Juliani, dkk., "Analisis Faktor Risiko Kelelahan Kerja Pada Karyawan Bagian Produksi Pt. Arwana Anugrah Keramik, Tbk". Jurnal Ilmu Kesehatan Masyarakat, vol. 9, no. 1, pp. 53-63, 2018.

[20] S. Narulita, N. Nilamsari, "Faktor Yang Berhubungan Dengan Kelelahan Pada Pekerja Dipo Lokomotif Pt. Kereta Api Indonesia (Persero)", Journal Of Industrial Hygiene And Occupational Health, vol. 3, no. 1, 2018. 